\title{
Smart Parking System: Technologies and Considerations
}

\author{
A. Kamala L, B. Hema K, C. Rajesh S M, D. Mohan Gowda V
}

\begin{abstract}
In today's world with a increase in economic behavior and standard of living people who own automobiles have increased recently and this leads to a rise in jams and car/vehicle parking rose to be a major problem. Searching for a parking space will be a major challenge and due to this a lot of traffic congestion will be created. Hence the solution to these can be found out in two ways one is using the intelligent parking system with image processing and second one is smart parking system based on reservation (SPSR) both of the above mentioned technology have been implemented in different ways and henceforth will find out which of the above two technology is efficient and see to it that the best solution to the problem can be obtained
\end{abstract}

Keywords: smart parking, modeling, automated parking, efficient parking, secured payment

\section{INTRODUCTION}

Finding a empty space for parking is a challenge in city area and a worry for motorists and is more hour consuming and this leads to lot of road congestion and pollution by voyaging the same location constantly in search of parking space

In a recent survey during peak time in big areas more jams generated due to finding of empty spaces is $40 \%$ of the average congestion and indirectly the time is wasted in search of empty slots/areas.

There are ways that are implemented in the manufacture of smart parking systems, less of which are listed as follows:

1. A method that is automatic and uses image processing techniques that uses the process of gamma correction by analyzing the traffic and edge values

2. A new methods has been identified which utilizes the identification of UAV images

3. SPSR using android, helps to notify the drivers about the empty spaces for parking

\section{LITERATURE SURVEY}

State of Art Parking management:

The studies of present space for approach for parking, explain their blocks and try to arouse different strategies for management of parking and traffic congestions.

Revised Manuscript Received on April 02, 2020.

* Correspondence Author

Kamala L*, Asst. Prof., Dept of CSE, GITAM School of Technology, Bengaluru, India E-mail: klakshmi@gitam.edu

B. Hema K, Asst. Prof., Dept of CSE, GITAM School of Technology, Bengaluru, India E-mail: hkrishna@gitam.edu

C. Rajesh S M, Asst. Prof., Dept of CSE, GITAM School of Technology, Bengaluru, India E-mail: rshivaga@gitam.edu

D. Mohan Gowda V, Asst. Prof., Dept of CSE, GITAM School of Technology, Bengaluru, India E-mail: mgowda@gitam.edu

(C) The Authors. Published by Blue Eyes Intelligence Engineering and Sciences Publication (BEIESP). This is an open access article under the CC BY-NC-ND license (http://creativecommons.org/licenses/by-nc-nd/4.0/)
1. Blind searching techniques: it is one of the simplest strategies used by the drivers to find the place to park the vehicle and in order to that they keep cruising around the same parking spaces and if they are not able to find one they just extend their area of searching and look for the parking space in parking lots.

2. Parking Information sharing (PIS) Mechanisms: the method proposes the present scenario of the design of the parking space, Here working mechanisms is as follows, the system of parking publishes the availability information of the area to the drivers in concerned area, then the chauffer's will conclude the empty space on the results obtained and there is a major disadvantage of this is that if the number of vacant/empty slots available is less in peak hours, then it will raise to increase demand for these slots which increases the traffic congestion and this mechanism is notified as "chasing multiple cars in single space"

Buffered parking information system(BPIS): this mechanism was proposed to address issues of "Multiple car chasing single space" problem, where architectures of the empty parking space modify PIS mechanisms and purposefully lessen the parking space when giving out live information of the spaces available i.e., to keep a buffer, here if the drivers are more waiting for spaces then the system as some extra spaces to reduce the conflicts here the problem is the shield is too small, then "chasing multiple cars in single space" issues will be raised if it's to big the usefulness of empty finding mechanism is process system where the driver swill make decisions based on the availability of spaces here the PIS and BPIS process allow chauffer's to analyses and conclude on the results of the current scenarios to lessen the congestion in finding the empty space for parking therefore the system gives the option for driver to choose appropriate space for alting the vehicle based on reservation systems methodology

\section{Parking system existing methodology}

Method based on Vision: this method requires a lot of ultrasonic sensors placed at each space or cameras that is installed at high altitudes and majorly can be bifurcated as follows:

1. It analyses the available spaces for the vehicle in the lot by taking count of incoming and outgoing vehicles

2. Maintaining total space available so that they can guide the car to vacant space.

Method based on sensors: here the sensors are of two types

1. Intrusive Sensors: are to be furnished on the pave surfaces by, holes under the surface are necessary.

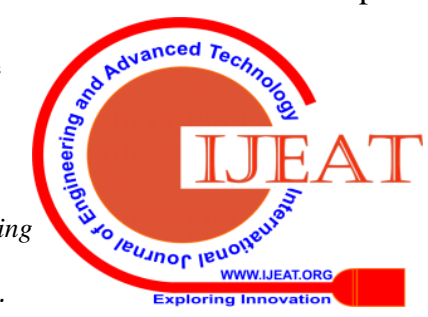


2. Non intrusive Sensors: needs to be attached on the roof or above the surface, ultrasonic sensors comes under this category and transmit sound waves from $25 \mathrm{KHZ}$ to $50 \mathrm{KHZ}$ and waves are emitted from sensors every 60 milliseconds, presence and, absentia of the automobiles are known only upon the differences obtained wrt to time the signals are sent and received.

Two tier parking and Automatic multilevel car parking System

This mechanism involves the parking of two cars one above the other in a single space here the upper level of parking is allocated rarely used car and frequently used car can be parked at lower level. This mechanism offers two systems:

1. Hydraulic system

2. Electro mechanical systems

They are fully or semiautomatic, manned or unmanned and can be installed above or below the ground

\section{Performance metrics:}

In this topic discussion is, the readiness of the chauffer's and their care towards the congestion and ecology savings.

1. Walking Distance: defines the minimum distance from the vehicle parking space to the destination, therefore chauffer's usually selects the empty space which is nearest to the destination and chauffer's satisfaction is important.

2. Traffic volumes: it is the amount or density at which congestion in parking is generated and also associated with air pollution

3. Challenges:

- Requires coordination among multiple drivers

- Identification of fake parking requests

- Users identity verification

- Delay in parking

- Timer

\section{IMPLEMENTATION}

\section{Two proposed methodologies:}

1. Using Image Processing: this methodology involves two modules

a. Vehicle module counting

b. Automatic module payment

The vehicle module counting take the count of number's automobiles parked at empty lot; the automatic payment module is consisting of RFID receiver and transmitter section.

Now let us discuss the implementation in detail:

a. Vehicle counting module: the modules are as follows:

1. Image input of parking lot: prototype of the module is developed for this system, and has four parking slots to park the vehicles, the images are has shown below

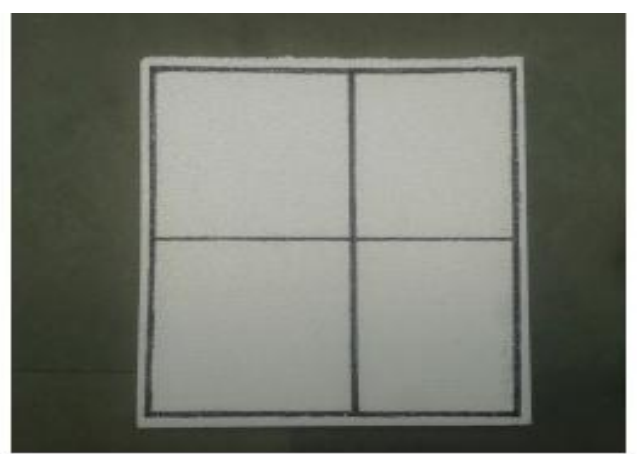

Fig 1: Empty parking Slot

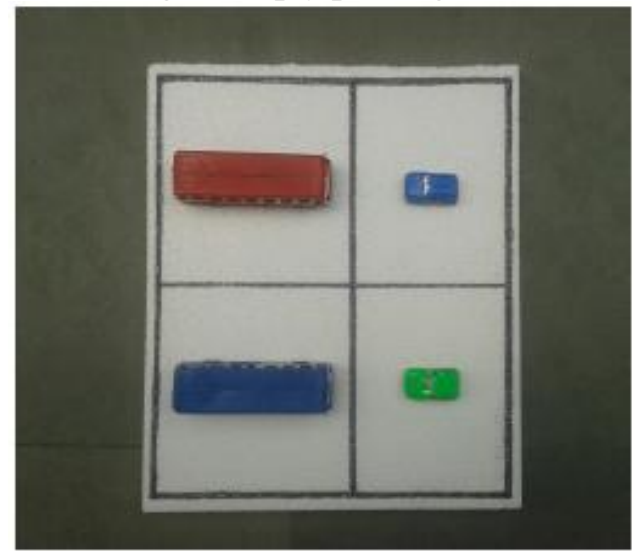

Fig 2: filled parking Slot

2. Extraction of features: the quality of features extracted from the image is directly dependent on the accuracy of the output.

3. ANN classification: the process involves the comparisons of the unknown input pattern to previously learned pattern

4. Output: the simulation of the output, obtained in MATLAB are the proof for the results for combining the various permutations of the sketched unit

\section{Automatic Module payment:}

1. Transmitting section: the unit combines the encoder, selector switch, Mc board, lcd display, step down transformer and information pertained to chauffer's are stored in the DB and RFID is provided to each chauffer's those are registered

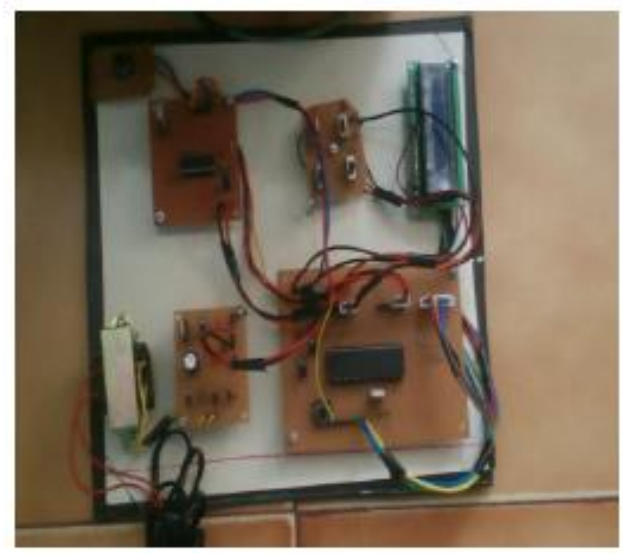

Fig 3: transmitter unit

Published By:

Blue Eyes Intelligence Engineering

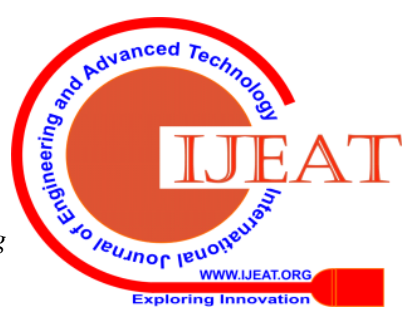


2. Receiver Section: the designed section involve the decoder, switch selector, micro-controller board, step down transformer, relay, and driver circuit. It allots the amount for parking charge and along with this an automatic gate set up model is implemented so that whenever the registered user enters in the gates open automatically. And the simulation results are as shown below:

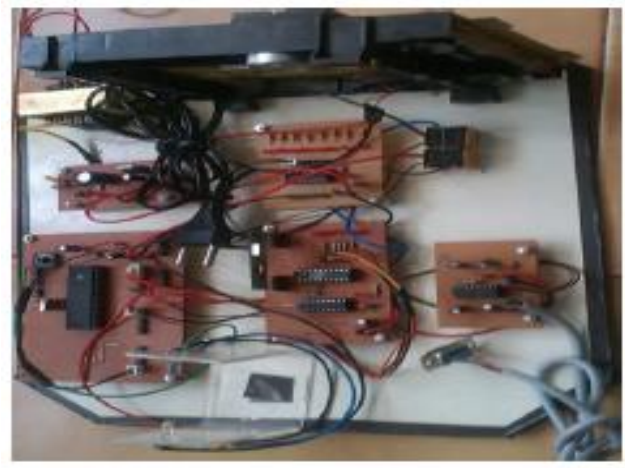

Fig 3: receiver unit

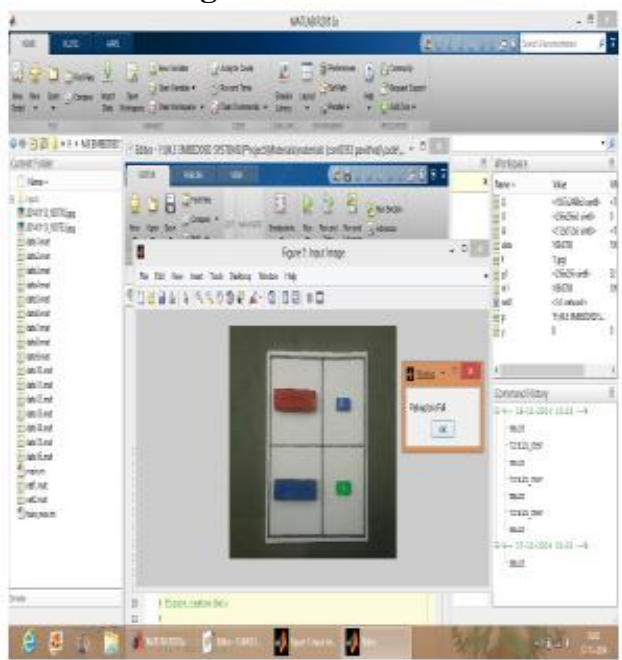

Fig 4: Simulated output when parking area is full

\section{Using Android}

In this methodology the user will get the information about the empty parking spaces and cost for the space and when the user registers for the space immediately, SPSR system gives the unique $\mathrm{QR}$ code message and dispatches it to the user and also displays total number of empty spaces available and occupied.

The system also analyzes traffic level, analyses the prices according to scheme of charging, displays information regarding QR code, amount and prices to the users and also stores them for further analysis.

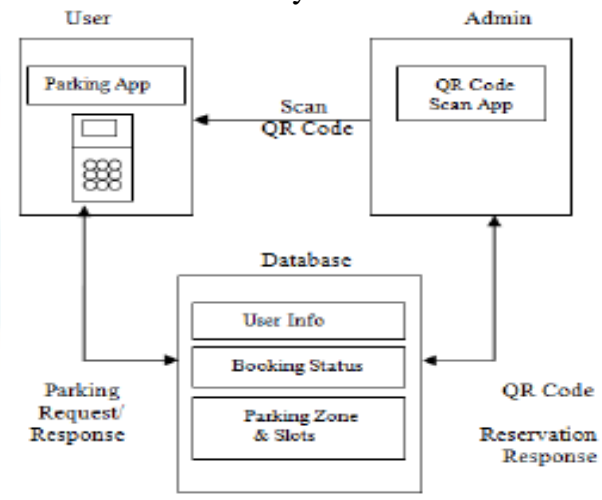

Fig 4: System Architecture
The system is analyzed into 3 major categories which are as follows scanner for QR code, centralized servers, and the mobiles as mentioned in below diagram and 2 major applications used are for the end user and the system admin. in empty space for the management of the parking and also congestion

The results of the parking comparisons under different parking guidance strategies are as shown below.

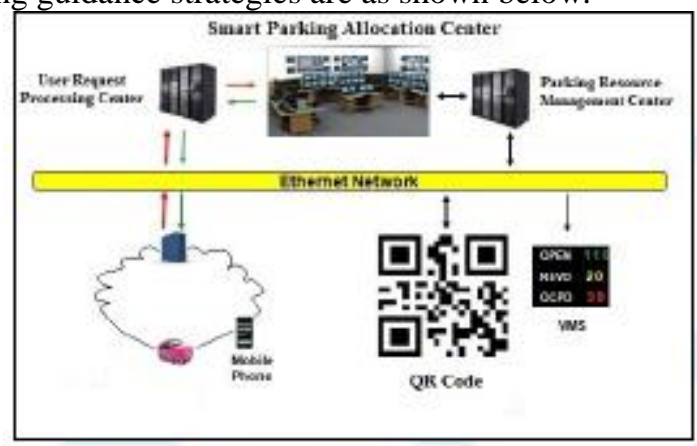

Fig 5: System hardware components

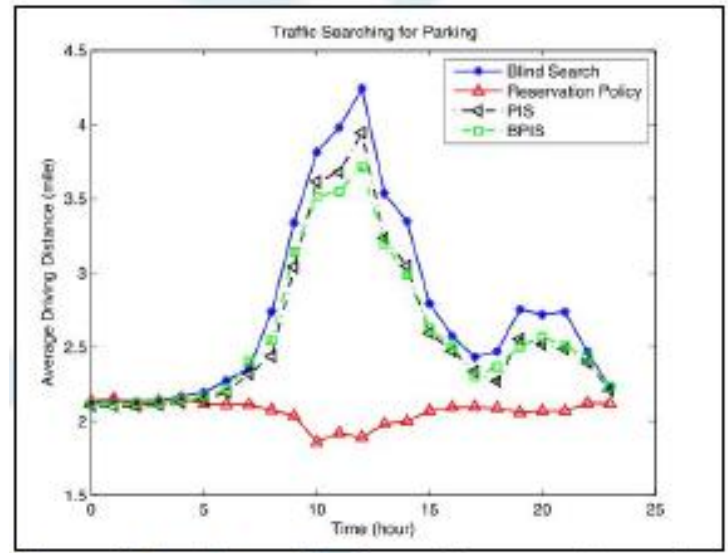

Fig 6: permutations for the guidance stratergies for parking

\section{CONCLUSION}

In above mentioned systems, the image processing methodology of implementation as its own advantages as follows:

- $\quad$ Noises are removed

- Density of image and contrast are correct

- $\quad$ Storage and retrieval is easy in computers

- Image of different kinds are available in any desired formats like black and white, negative image

Whereas when we look into the second methodology of SPSR system(android) with respect to android is efficient but not up to mark as that of image processing because of the following disadvantages

- Coding is more with respect to java and objective C

- Coding is much harder with respect to complex layouts and animations

- $\quad$ Prone to virus attack in android market

- Quick drain in power of phones because of the lot of process in background

- Fragmentation of the high

Published By:

Blue Eyes Intelligence Engineering \& Sciences Publication

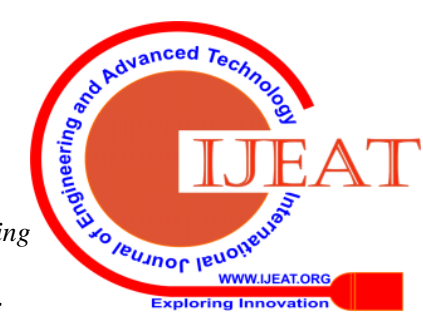


So we consider image processing to be better methodology when compared to android application.

\section{FUTURE ENHANCEMENTS}

The application in image processing can be further extended using Automatic Number Plate Recognition Solution which is more efficient in terms of parking management and controlling the violations in the traffic and hence helps in building of smart cities and make it a better place to live.

\section{REFERENCES}

1. P. White, "No Vacancy: Park Slopes Parking Problem and How to Fix It," http://www.transalt.org/

2. "Solutions for Improving City Operations,'http://www.streetlinenetworks.com/site/index.php

3. W. Mao, Modern Cryptography: Theory and Practice,Prentice Hall PTR

4. M. Feldman, K. Lai and L. Zhang, "A Price-Anticipating Resource Allocation Mechanism forDistributed Shared Clusters," in Proceedings of the 6th ACM conference on Electronic commerce

5. Amin Kianpisheh,Norlia Mustaffa, Pakapan Limtrairut and Pantea Keikhosro kiani,"Smart parking system (SPS) architecture using Ultrasonic Detector" in International Journal of Software Engineering and Its Applications

6. Chihping Hsu, Toshimitsu Tanaka, Noboru.Sugie, KouziUeda," Locating Vehicles in a Parking Lot by Image Processing”, IAPR Workshop on Machine Vision Applications, Dec. 11-13, 2002, Naraken New Public Hall, Nara, Japan,pp.475-478

7. SIPARK PMA Press Release, Siemens Corporate Website, http://w1.siemens.com/ press/en/pr_cc/2007/06_jun/is05076241e_1451454.htm

8. Chung-cheng chiu, Min-yu ku, Chun-yi wang, "Automatic Traffic Surveillance System for Vision-Based Vehicle Recognition and Tracking",

9. W. Shao, W. Yang, G. Liu, and L. J. , "Car detection from highresolution aerial imagery using multiple features," in Proc. IGARSS, 2012, pp. 4379-4382.

10. T. Zhao and R. Nevatia, "Car detection in low resolution aerial images," in Proc. IEEE Int. Conf. Comput. Vis., 2001, pp. 710-717.

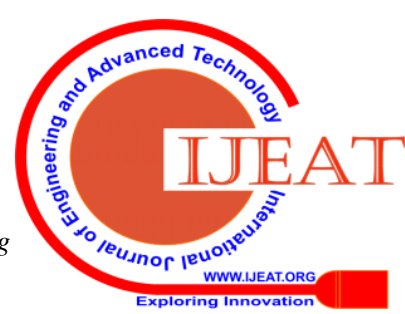

